\title{
Studies on the Mechanism of Ristocetin-Induced
}

\section{Platelet Agglutination}

\author{
EFFECTS OF STRUCTURAL MODIFICATION OF \\ RISTOCETIN AND VANCOMYCIN
}

\author{
Barry S. Coller and Harvey R. Gralnick \\ From the Hematology Service, Clinical Pathology Department, Clinical Center, National Institutes \\ of Health, Bethesda, Maryland 20014
}

\begin{abstract}
A B S T R A C T The mechanism by which ristocetin induces platelet agglutination in the presence of the von Willebrand factor was studied by chemically altering ristocetin and a similar antibiotic, vancomycin, by reaction with a water-soluble carbodiimide in the presence of glycine methyl ester at $\mathrm{pH} 4.75$. Altering ristocetin's phenolic groups (which are thought to be important in its peptide-binding properties) resulted in a loss of both plateletagglutinating and antibiotic activities. Restoring the phenolic groups with hydroxylamine restored both activities.

Vancomycin has antibiotic and peptide-binding properties similar to ristocetin's, but differs structurally in having a free carboxyl group and thus a less positive charge at neutral $\mathrm{pH}$. It does not induce platelet agglutination and actually inhibits ristocetininduced agglutination. Reacting vancomycin with the water-soluble carbodiimide resulted in alteration of phenolic groups and permanent conversion of the carboxyl to a neutral derivative. Restoring the phenolic groups with hydroxylamine (but leaving the carboxyl neutralized) produced a compound with charge properties similar to ristocetin's which induced platelet agglutination as ristocetin does.
\end{abstract}

These data suggest both a binding requirement (mediated through phenolic groups) and a strong positive charge requirement for ristocetin-induced agglutination. The data are consistent with a model

Dr. Coller's current address is the Division of Hematology, Department of Medicine, State University of New York at Stony Brook, Health Sciences Center, Stony Brook, N.Y. 11794.

Received for publication 16 December 1976 and in revised form 24 March 1977. wherein positively charged ristocetin binds, via its phenolic groups, to sites on the platelet surface and reduces the platelet's negative charge. This could reduce the electrostatic repulsion between platelets and/or between platelets and the negatively charged von Willebrand factor, and permit the macromolecular von Willebrand factor to cause agglutination by bridging between platelets.

\section{INTRODUCTION}

In 1971, Howard and Firkin observed that the antibiotic ristocetin induced platelet aggregation in normal platelet-rich plasma (1). It is now known that this phenomenon requires: $(a)$ a plasma factor activity absent or decreased in von Willebrand's disease (1-3), and $(b)$ a platelet factor missing or decreased in the Bernard-Soulier syndrome (4). This platelet factor is not affected by formalinization (5) but is decreased by proteolytic enzyme treatment (6). Whereas previous studies (7-9), including our own $(10,11)$, support an electrostatic mechanism of aggregation, the precise manner in which ristocetin interacts with these two factors remains unknown.

The molecular structure of ristocetin (which actually is composed of two closely related compounds, ristocetins $A$ and $B$ ) is not completely known, but current data suggest that it consists of a cyclic dipeptide aglycone to which various sugars (including a unique aminosugar) are attached (12). Titration analysis revealed phenolic and amino groups, with an isoionic point of 8.2-8.3 (13).

Studies of ristocetin's antimicrobial activity showed that it can bind to specific peptides with configurations similar or identical to intermediates in bacterial cell wall synthesis (14). This binding had an 
absolute requirement for a terminal, ionized carboxyl group on the peptide, and titration analysis indicated that ristocetin's phenolic groups take part in the binding reaction. McFarlane recently showed that these ristocetin-binding peptides can inhibit ristocetin-induced platelet agglutination (15), suggesting that the peptides can compete for the available ristocetin.

Vancomycin is an antibiotic similar to ristocetin in structure (16), antimicrobial spectrum (17), mechanism of action, and peptide-binding properties (18). We have previously shown that it does not aggregate platelets as ristocetin does (19), and a preliminary report indicated that it actually inhibits ristocetin-induced platelet aggregation (20). Vancomycin, unlike ristocetin, contains a single ionizable carboxyl group, in addition to its amino and phenolic groups (13). This results in vancomycin having a less positive net charge than ristocetin at neutral $\mathrm{pH}$. Since we previously postulated that ristocetin's ability to induce aggregation depended upon it having a net positive charge (based on the coincidence of the upper $\mathrm{pH}$ limit of ristocetin-induced platelet aggregation [8.3-8.5] with its isoionic point [8.2-8.3]), this charge difference may account for vancomycin's inability to induce agglutination.

To investigate the mechanism of ristocetin-induced agglutination, we modified both ristocetin and vancomycin by reaction with the water-soluble carbodiimide 1-(3-dimethylaminopropyl)-3-ethyl carbodiimide (EDC), ${ }^{1}$ at $\mathrm{pH} 4.75$, in the presence of the nucleo-

${ }^{1}$ Abbreviations used in this paper: EDC, 1-(3-dimethylaminopropyl)-3-ethyl carbodiimide; OD, optical density; PRP, platelet-rich plasma. phile glycine methyl ester. Under these conditions, both phenolic and carboxyl groups will react $(21,22)$, yielding an $\mathrm{O}$-aryl isourea and the neutral glycine methyl ester derivative of the carboxylic acid, respectively (Fig. 1). Both reactions consume hydrogen ions so that the amount of acid required to maintain a constant $\mathrm{pH}$ can be used as a rough measure of the extent of the reaction. The phenolic group can be regenerated from the $\mathrm{O}$-aryl isourea by reaction with hydroxylamine (22), but the carboxylic acid derivative is not reversible with hydroxylamine. Thus, with ristocetin, which contains phenolic but not carboxylic acid groups, the reaction will alter the phenolic groups which can then be regenerated with hydroxylamine. Vancomycin, on the other hand, will undergo modification of both its phenolic and carboxylic acid groups. Subsequent reaction with hydroxylamine will regenerate the phenolic groups but not the carboxylic acid group. Since the carboxyl derivative is uncharged at neutral $\mathrm{pH}$, the net charge of the vancomycin will be made more positive, that is, more like ristocetin's. Thus, these reactions permitted us to investigate the importance of the phenolic groups (presumed to be important in the binding reactions) and the net molecular charge in ristocetin-induced agglutination.

\section{METHODS}

Ristocetin (lot 54-182-BW) was obtained from Abbott Laboratories (North Chicago, Ill.) and vancomycin hydrochloride (Vancocin $\mathrm{HCl}$ ) was obtained from Eli Lilly and Company (Indianapolis, Ind.). The manufacturer states that this ristocetin preparation contains more than $90 \%$ ristocetin $A$ and the remainder is ristocetin $B$ as determined by paper chromatography. Before reaction with the carbodiimide, vancomycin hydrochloride was purified by ion-exchange
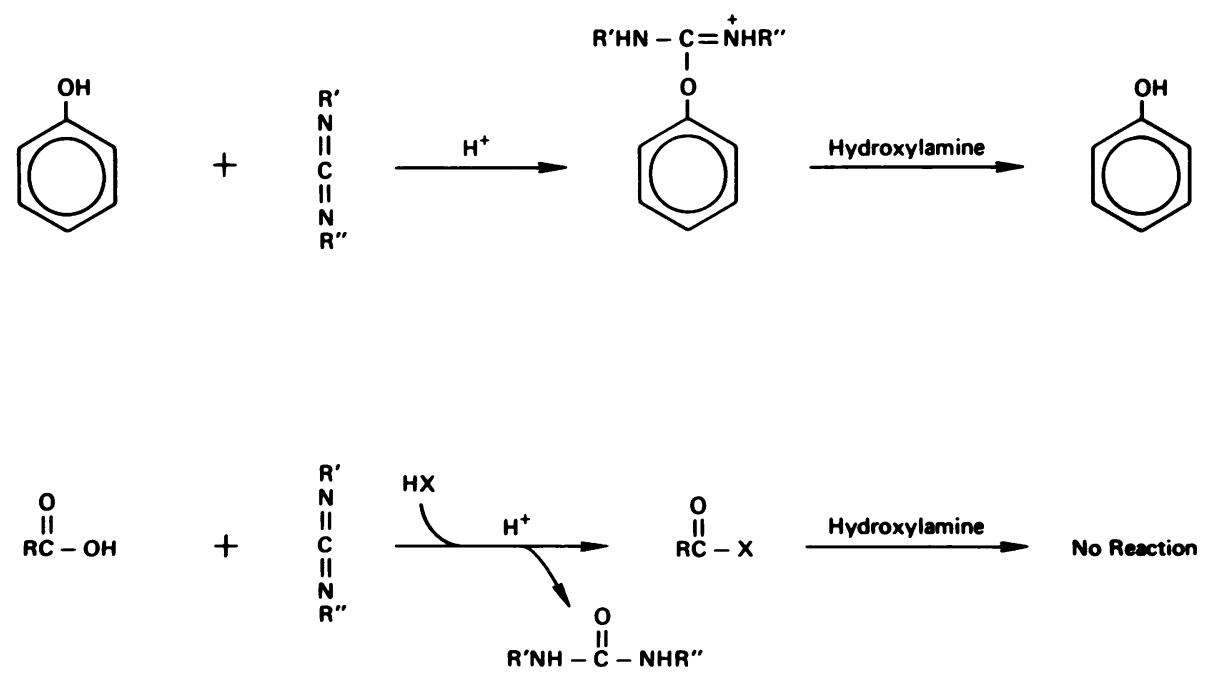

FIGURE 1 Reactions occurring between water-soluble carbodiimide and phenolic and carboxyl groups. HX represents any nucleophile. 
chromatography on CM-Sephadex C-50 (Pharmacia, Fine Chemicals, Piscataway, N.J.) as previously described (19). The fraction IV, which contained approximately $90 \%$ of the total antibiotic eluted, was desalted and concentrated by diafiltration using a membrane with a $1,000-$ mol wt exclusion (UM-2, Amicon Corp., Lexington, Mass.) and used in all subsequent experiments. Analytical calculations were based upon $E_{1 \mathrm{~cm}}^{1 \%}$ values of $49 \pm 1$ at $280 \mathrm{~nm}$ for ristocetin (14), 46 \pm 1 for vancomycin hydrochloride (13), and $45 \pm 1$ for fraction IV of purified vancomycin (18).

Antibiotic activity of vancomycin, ristocetin, and their derivatives was measured by a standard technique (23) with several modifications. Bacillus subtilis spore suspension (Baltimore Biological Laboratories, Baltimore, Md.) was mixed with standard medium number 5 , and $9 \mathrm{ml}$ of this seeded agar was poured into each petri dish. Measured aliquots of the antibiotic solutions were added to paper disks which were then placed on the seeded agar and incubated overnight at $35^{\circ} \mathrm{C}$. A reference curve was prepared from serial dilutions $(100-6.25 \mu \mathrm{g} / \mathrm{ml})$ of the unmodified antibiotic, plotting the average diameter of the zone of inhibition versus the log of the concentration. The antibiotic activity of one or two dilutions of the modified antibiotics was read from the standard curves. Samples whose diameters did not fall on the standard curve were retested at an appropriate dilution. All samples (reference and unknown) were tested six times in each assay and the values were averaged. In addition, a plate standard (dilution of reference sample) was included in each dish to correct for variations in growth between dishes.

Electrometric titrations, carried out in a water-jacketed titration vessel maintained at $24^{\circ} \mathrm{C}$, were performed with a Beckman pHasar-I pH meter and a Beckman combination $\mathrm{Ag}-\mathrm{AgCl}$ electrode (39505) (Beckman Instruments, Inc., Fullerton, Calif.) Samples were made $0.2 \mathrm{M}$ in $\mathrm{KCl}$, and the $1 \mathrm{~N} \mathrm{HCl}$ and $1 \mathrm{~N} \mathrm{NaOH}$ standards (SO-A-48, Fisher Scientific Co., Pittsburgh, Pa. and 1306 D, Harleco, Gibbstown, N.J.) were diluted in $0.2 \mathrm{M} \mathrm{KCl}$ to their final concentrations. Electrode leak of $\mathrm{KCl}$ over the time required for a titration resulted in less than a $0.2 \%$ increase in $\mathrm{KCl}$ concentration. The electrodes were calibrated before each measurement with standard buffers of $\mathrm{pH} 4.01$ and 7.00 and checked for drift after each titration. Glass distilled water, boiled and cooled under $\mathrm{N}_{2}$, was used to prepare dilutions of the samples and standards. Titrations in the alkaline range were conducted under continuous bubbling with $\mathrm{N}_{2}$. Additions of acid or base were made with a $0.2-\mathrm{ml}$ micrometer buret (Gilmont S1100A, Roger Gilmont Instruments, Inc., Great Neck, N.Y.). Vancomycin and its derivatives were titrated at an $\mathrm{OD}_{280}$ of 4.6 corresponding to an unaltered vancomycin concentration of $1 \mathrm{mg} / \mathrm{ml}$ with $0.1 \mathrm{M} \mathrm{NaOH}$ and either 0.5 or $0.01 \mathrm{M} \mathrm{HCl}$. Ristocetin and its derivatives were titrated at an $\mathrm{OD}_{280}$ of 3.8 , corresponding to an unaltered ristocetin concentration of $0.8 \mathrm{mg} / \mathrm{ml}$. All titrations were performed on 3-ml samples. No correction for $\mathrm{Na}^{+}$was made since even at $0.1 \mathrm{M} \mathrm{Na}^{+}$(15 times higher than the highest $\mathrm{Na}^{+}$concentration achieved in these studies) the $\mathrm{pH}$ correction for this type of glass at $25^{\circ} \mathrm{C}$ is only $0.05 \mathrm{U}$ at $\mathrm{pH}$ 11.0.

Titration data were expressed as total micromoles of $\mathrm{H}^{+}$ bound or dissociated for each sample and were calculated as the difference between the micromoles of acid or base added and the micromoles of $\mathrm{H}^{+}$or $\mathrm{OH}^{-}$free in solution. The number of these free ions was calculated from the volume of solution and the free concentrations of the ions as determined from the titration curve of $\mathrm{H}_{2} \mathrm{O}$. All titration data were reported without adjustment except the hydroxylamine-treated vancomycin-EDC derivative where, for purposes of comparison of dissociation constants, the values were reduced by a factor of 0.38 to make the total micromoles of the $\mathrm{H}^{+}$dissociated equivalent to that of the untreated vancomycin. Since the shapes of the curves in the alkaline region were identical (as contrasted to the shift to the left in pK's of the vancomycin-EDC derivative), the differences in total $\mathrm{H}^{+}$dissociated probably reflected a higher concentration of the derivative as a result of a reduction in extinction coefficient from the introduction of the carboxyl group modification.

Spectroscopic studies to test for phenolic group alterations in ristocetin were conducted in a Gilford spectrophotometer (model 240, Gilford Instrument Laboratories, Inc., Oberlin, Ohio). Ristocetin and its derivatives were prepared in deionized water to a final volume of $1 \mathrm{ml}$ at approximately the same $\mathrm{OD}_{280}$ and adjusted to $\mathrm{pH} 7$ by the addition of $1 \mathrm{~N} \mathrm{NaOH}$ (less than $1 \mu l$ ). Optical density readings were taken at multiple wavelengths between 270 and $305 \mathrm{~nm}$ on each sample. The samples were then adjusted to $\mathrm{pH} 11$ with $1 \mathrm{~N} \mathrm{NaOH}$ (less than $2.5 \mu \mathrm{l}$ for any sample) and the readings repeated.

The water-soluble carbodiimide reactions were carried out at $\mathrm{pH} 4.75$ according to the method of Hoare and Koshland (21). $5 \mathrm{ml}$ of aqueous solutions of ristocetin (15 or $25 \mathrm{mg} / \mathrm{ml}$ ) or vancomycin fraction IV $(6.1 \mathrm{mg} / \mathrm{ml})$ were made $1 \mathrm{M}$ in glycine methyl ester and placed in a water-jacketed reaction vessel maintained at $24^{\circ} \mathrm{C}$. The solutions were adjusted to $\mathrm{pH}$ 4.75 and the reaction initiated by adding $0.5 \mathrm{ml}$ of $1 \mathrm{M}$ EDC adjusted to $\mathrm{pH} 4.75$. The solution was stirred constantly by a magnetic stirrer and the $\mathrm{pH}$ maintained at 4.75 by manual addition of $1 \mathrm{~N} \mathrm{HCl}$ with a micrometer buret. At 1-min intervals, the volume of acid added to maintain the $\mathrm{pH}$ was recorded. Aliquots were removed periodically for monitoring $\mathrm{OD}_{280}$ and platelet-clumping activity. The progress of the reaction was followed by the rate of consumption of acid. This was rapid at first and then diminished to near zero at approximately 110-130 min. The low molecular weight reactants were removed from the antibiotic by diafiltration in an Amicon device fitted with a 1,000 -mol wt cut-off membrane (UM-2). Diafiltration was accomplished either by repeated cycles of concentration followed by the addition of deionized water, or the use of a reservoir which continuously replaced the diafiltrate with deionized water. The process was terminated and the samples concentrated when the conductivity of the diafiltrate decreased to a constant value $(90-350 \mu \mathrm{mho} / \mathrm{cm})$. The reaction of the phenolic groups with EDC was reversed by mixing equal volumes of the diafiltered and concentrated antibiotic-EDC derivative with $1 \mathrm{M}$ hydroxylamine, $\mathrm{pH} 7.0$, at $25^{\circ} \mathrm{C}$ for $4 \mathrm{~h}$. The samples were then diafiltered (to remove the low molecular weight hydroxylamine) and concentrated as described above.

Ristocetin-induced platelet agglutination was performed by modifying the previously described (10) formalin-fixed platelet assay for von Willebrand factor. To test the clumping ability of ristocetin during the EDC reaction, 25- $\mu$ l aliquots of the reaction mixture were added to test tubes containing $0.4 \mathrm{ml}$ of washed, formalinized platelets (adjusted to $300,000 / \mathrm{mm}^{3}$ ) and $50 \mu \mathrm{l}$ of a reference plasma (either a pool of 10 normal citrated plasmas or a lyophilized reference plasma [QPak, Hyland Div., Travenol Laboratories, Inc., Costa Mesa, Calif.]). The time for macroscopic clumping to occur was then recorded. Preliminary experiments revealed that glycine methyl ester had no effect on the assay at the concentrations used in the reaction. A log-log standard curve was constructed from the clumping times of ristocetin-1 M glycine methyl ester at the same concentration used in the reaction and dilutions of this solution prepared in $1 \mathrm{M}$ glycine methyl ester. The clumping time produced by aliquots of the reaction mixture at intervals after the reaction was begun 
could then be converted into a percentage of the original clumping activity of the ristocetin. In a similar manner, the restoration of clumping activity produced by reaction with hydroxylamine was followed by adding $50 \mu$ l (used early in the reaction for low levels of clumping activity) or $20 \mu \mathrm{l}$ (used late in the reaction for higher levels of clumping activity) of the reaction mixture to the platelet-reference plasma mixture and determining the clumping time. Preliminary experiments showed that hydroxylamine, at the dose used, had no effect on the assay. The percentage of activity restored was derived from two standard curves of clumping times of dilutions of ristocetin-hydroxylamine in $0.5 \mathrm{M}$ hydroxylamine using either 50- or 20- $\mu$ l aliquots. To be certain that the restored clumping activity was not due to a nonspecific plasma protein precipitation reaction, severe von Willebrand plasma ( $<3 \%$ von Willebrand factor) was substituted for the reference plasma. To assay for ristocetin-like clumping activity in vancomycin and its derivatives, $75 \mu \mathrm{l}$ of the solutions $\left(\mathrm{OD}_{280}=29\right.$ in one experiment and 23 in another, equivalent to unaltered vancomycin concentrations of 6.3 and $5 \mathrm{mg} / \mathrm{ml}$ ) was added to test tubes containing $0.4 \mathrm{ml}$ of platelets and $50 \mu \mathrm{l}$ of reference plasma, hemophilic plasma, or severe von Willebrand plasma.

The assay was modified to test the inhibitory effect of vancomycin fraction IV. Preliminary experiments to ascertain the time course of inhibition were performed by adding 20 or $40 \mu \mathrm{l}$ of vancomycin fraction IV at $6.6 \mathrm{mg} / \mathrm{ml}$ to $0.4 \mathrm{ml}$ of platelet suspension for up to 2 min either with or without mixing. The reference plasma $(50 \mu \mathrm{l})$ was then added, followed $30 \mathrm{~s}$ later by $5 \mu \mathrm{l}$ of the ristocetin $(50 \mathrm{mg} / \mathrm{ml})$. Inhibition was found to increase with incubation time, reaching a plateau within $30 \mathrm{~s}$ if the test tubes were constantly mixing. With a final concentration of $0.53 \mathrm{mg} / \mathrm{ml}$ vancomycin, the clumping time increased from 18 to $71 \mathrm{~s}$ and with $0.28 \mathrm{mg} / \mathrm{ml}$ vancomycin, it increased from 14 to $23 \mathrm{~s}$ with $30 \mathrm{~s}$ of premixing. To standardize this variable, later studies were performed with precisely $45 \mathrm{~s}$ of mixing. These studies employed $0.4 \mathrm{ml}$ of platelet suspension mixed with $10 \mu \mathrm{l}$ vancomycin fraction IV. $(5.7-22.6 \mathrm{mg} / \mathrm{ml})$ after which $50 \mu \mathrm{l}$ of a 1/2 dilution of the reference plasma was added. $30 \mathrm{~s}$ later, $5 \mu \mathrm{l}$ of ristocetin $(30-50 \mathrm{mg} / \mathrm{ml})$ was blown in and the clumping time determined. In other experiments to determine the locus of vancomycin's inhibition, preincubation of the platelets with vancomycin for variable periods of time was compared to preincubation of vancomycin with the reference plasma. These studies employed $0.4 \mathrm{ml}$ of platelets, $5 \mu \mathrm{l}$ of vancomycin fraction IV at $22.6 \mathrm{mg} / \mathrm{ml}, 50 \mu \mathrm{l}$ of undiluted reference plasma, and $5 \mu \mathrm{l}$ of ristocetin $(50 \mathrm{mg} / \mathrm{ml})$.

Platelet aggregation was performed on citrated plateletrich plasma in a Chrono-Log aggregometer (Chrono-Log Corp., Havertown, Pa.) as previously described (10). All samples were maintained at $\mathrm{pH} 7.70 \pm 0.05 \mathrm{U}$ by controlling the $\mathrm{pCO}_{2}$ environment as previously described (10), and a Tefloncoated stir bar $(2.4 \times 4.75-\mathrm{mm})$ was used for all studies $(24)$. $25 \mu \mathrm{l}$ of water or vancomycin fraction IV in water $(15,7.5$, and $3.75 \mathrm{mg} / \mathrm{ml})$ was added to samples of PRP $(0.4 \mathrm{ml}$; 300,000 platelets $/ \mathrm{mm}^{3}$ ) which had previously established a base line optical density (OD). After exactly $1 \mathrm{~min}, 15$ $\mu l$ of ristocetin $(50 \mathrm{mg} / \mathrm{ml})$ was added and the change in OD was recorded. Quantitation was obtained by measuring the initial slope of aggregation and expressing it as OD units/minute.

Glycine methyl ester hydrochloride, EDC, and hydroxylamine hydrochloride were obtained from Aldrich Chemical Co., Inc. (Milwaukee, Wis.). Trizma-HCl was obtained from Sigma Chemical Co. (St. Louis, Mo.).

\section{RESULTS}

In all four experiments, reacting ristocetin with EDC led to a decrease in platelet-agglutinating activity. The results of one of these experiments are shown in Fig. 2. The amount of acid added was a measure of the extent of the reaction. The ability of ristocetin to agglutinate platelets decreased to $90 \%$ of its original activity immediately after the addition of the 1/10 vol of EDC and then continued to decrease over time. By $25 \mathrm{~min}$, the clumping activity was reduced to the lower limit of sensitivity of the assay $(21 \%)$ and so could not be accurately measured further. At the end of the reaction and after removing the EDC and glycine methyl ester, the antibiotic activity of the altered ristocetin was $24 \%$ (average of two experi-

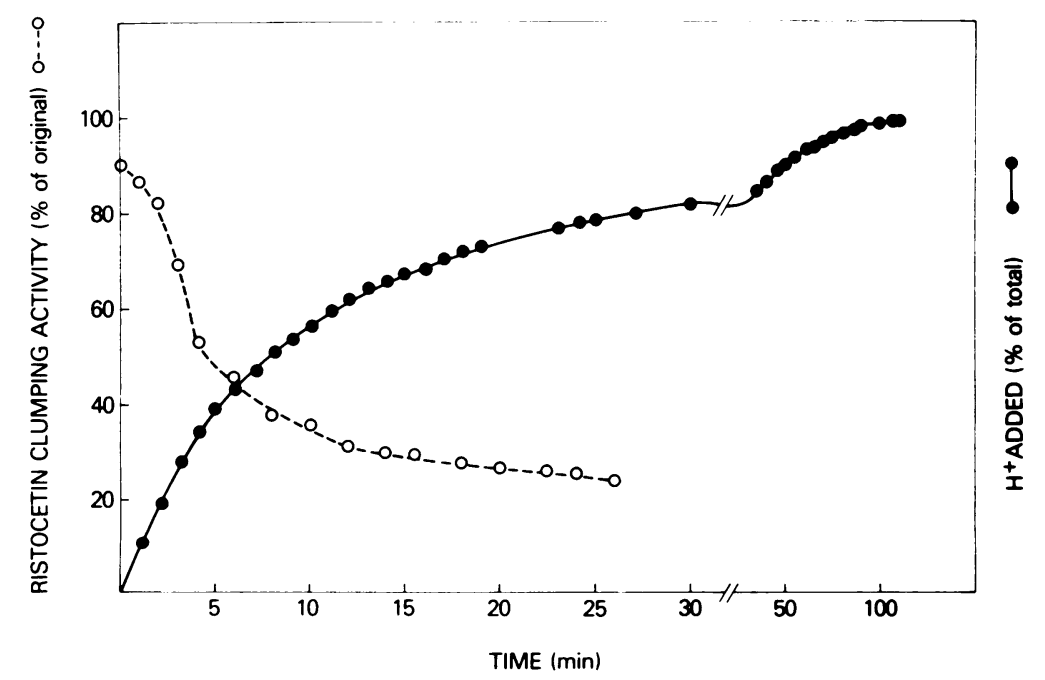

FIGURE 2 The effect of the EDC reaction on ristocetin's clumping activity. The $\mathrm{H}^{+}$added is an index of the extent of the reaction. 
ments) of its original activity. No significant change in the absorbance at $280 \mathrm{~nm}$ of the solution occurred during the EDC reaction. The effect of phenolic group restoration by hydroxylamine on the clumping activity of ristocetin is shown in Fig. 3. As the reaction proceeded the clumping activity was restored, reaching essentially $100 \%$ of its original activity. When severe von Willebrand plasma was substituted for the reference plasma there was no clumping, showing that the restored clumping activity was not due to nonspecific precipitation of plasma proteins. The antibiotic activity, tested after $180 \mathrm{~min}$, was restored to $65 \%$ (average of two experiments) of its original activity.

The spectrophotometric studies of ristocetin and its derivatives are shown in Fig. 4. The absorption of phenolic groups undergoes a shift to a longer wavelength when the phenolic group is ionized at high $\mathrm{pH}$ (12). Since phenolic groups reacted with EDC cannot ionize, they should show no shift at high pH. Thus, if some of the phenolic groups have been converted by reaction with EDC, there will be less shift of the absorption peak at high $\mathrm{pH}$. At $\mathrm{pH} 7$, the curves of

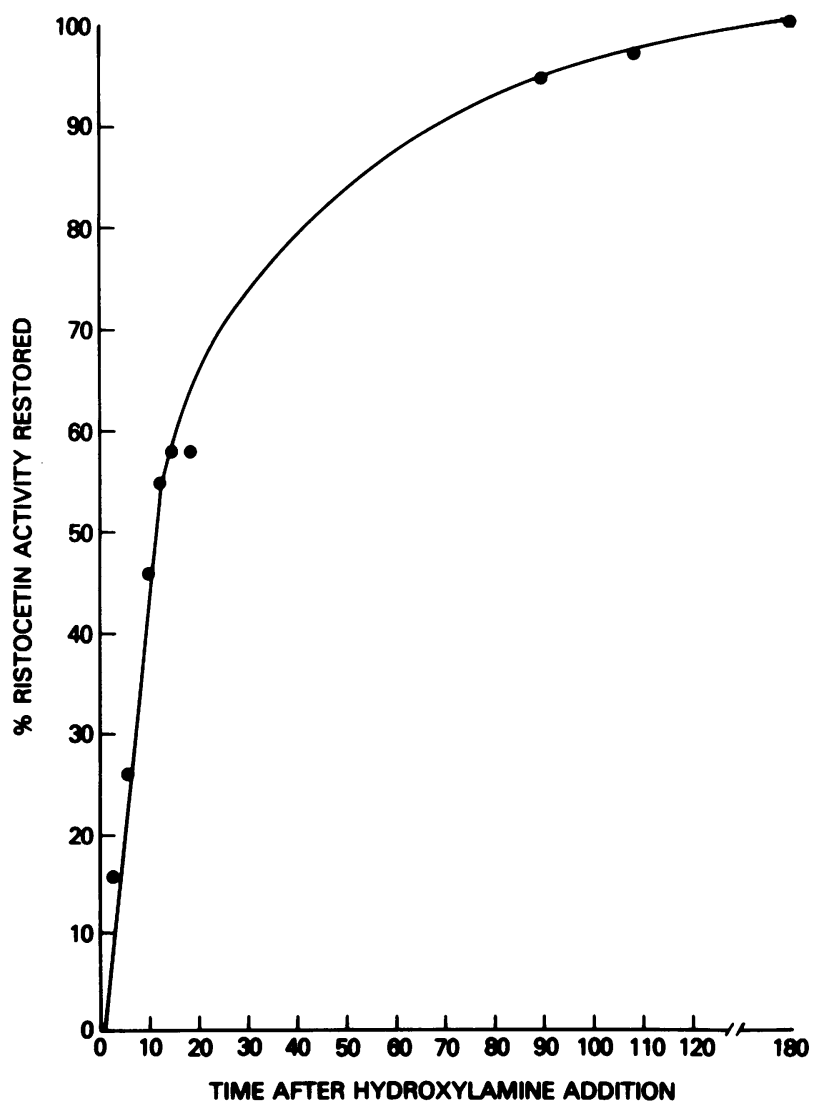

FIGURE 3 Restoration of ristocetin's clumping activity by reacting the EDC derivative with hydroxylamine. The time scale is in minutes.

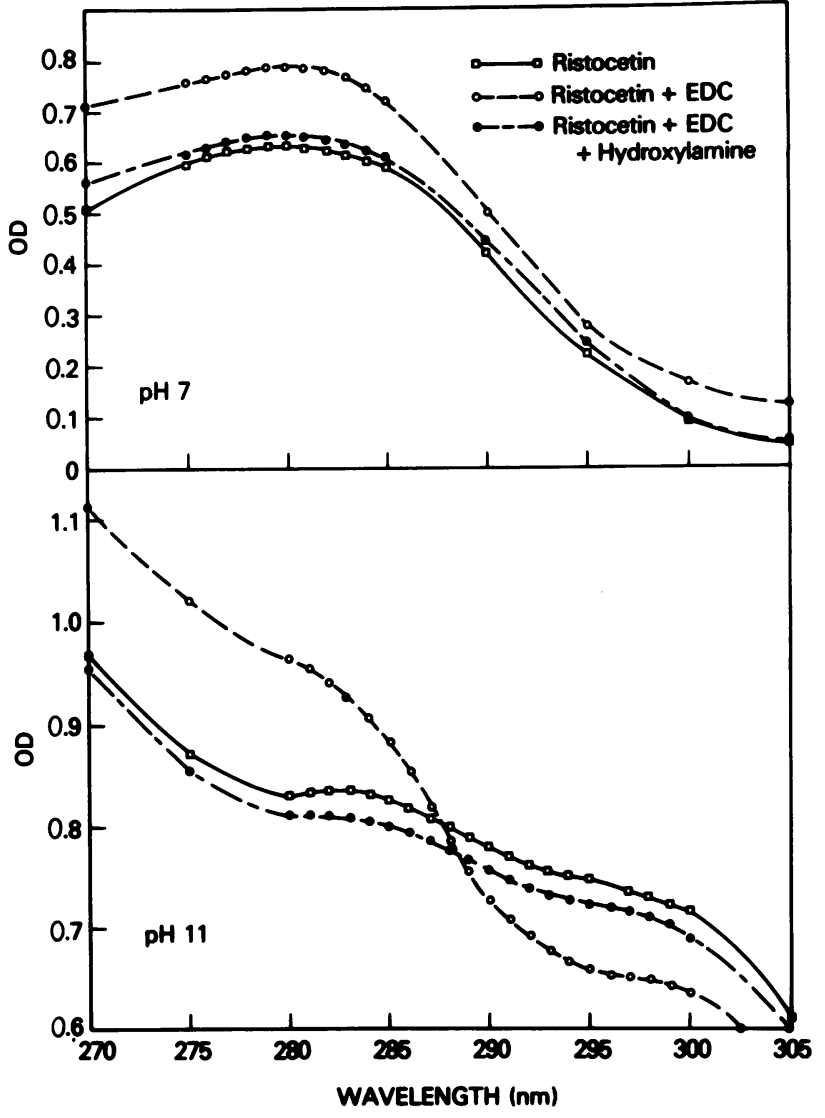

FIGURE 4 Absorption spectra of ristocetin and its derivatives at $\mathrm{pH} 7$ and 11 .

ristocetin and ristocetin + EDC + hydroxylamine are nearly identical. The ristocetin + EDC curve is similar although there is slightly less curvature at the lower wavelengths. At $\mathrm{pH} \mathrm{11}$, again the ristocetin and ristocetin + EDC + hydroxylamine curves are nearly identical with an overall increase in absorbance and a broadening of the absorbance peak out to $300 \mathrm{~nm}$. The ristocetin + EDC absorption spectrum is much different with a pattern that more closely approximates the pattern at $\mathrm{pH} 7$. This suggests that the ristocetin + EDC derivative is less affected by a change in $\mathrm{pH}$ which is consistent with an alteration which prevents ionization of some of the phenolic groups.

The alkaline electrometric titration data of ristocetin and its derivatives are shown in Fig. 5. Preliminary titration data in both the acid and alkaline regions confirmed the previously reported pattern (13) from which it was concluded that there are two amino and five phenolic groups. The curves for ristocetin and ristocetin + EDC + hydroxylamine are virtually identical suggesting complete reversal of the EDC reaction by hydroxylamine. The ristocetin + EDC curve, on the other hand, reaches a higher plateau and is shifted 


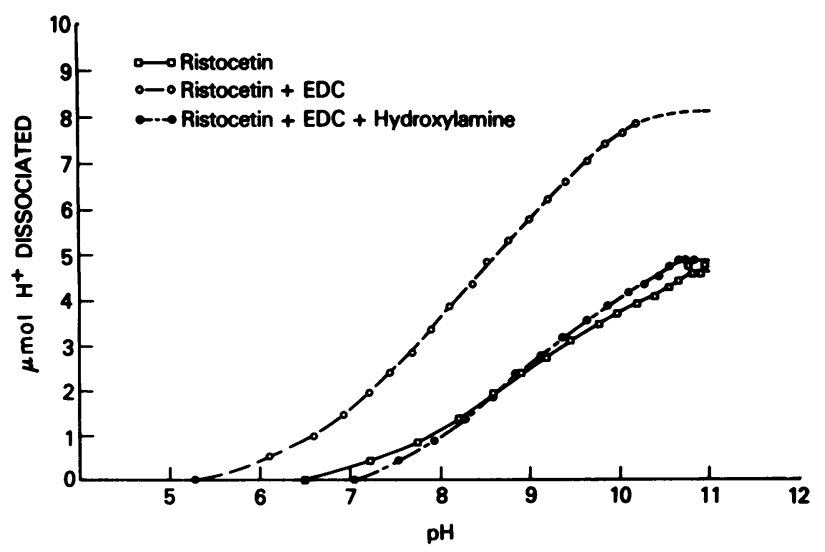

FIgURE 5 Electrometric titration of $2.4 \mathrm{mg}$ of ristocetin and its derivatives.

to the left. The higher plateau is accounted for by the substitution of two ionizable groups by the EDC for each phenolic group altered. The two ionizable groups are the isourea nitrogen (Fig. 1) and the amino nitrogen in the dimethylaminopropyl group constituting $\mathbf{R}^{\prime}$ in Fig. 1. The number of phenolic groups altered can theoretically be calculated from the increased amount of $\mathrm{H}^{+}$dissociated since two ionizable groups are being substituted for a single one. In two experiments the ratios of the total micromoles of $\mathrm{H}^{+}$dissociated from ristocetin divided by the total micromoles of $\mathrm{H}^{+}$dissociated from ristocetinEDC were 0.64 and 0.65 . This is consistent with the conversion of four of the five phenolic groups by EDC since the initial ristocetin has seven ionizable groups (two amino and five phenolic) and if the derivative had 11 groups, this would yield a ratio of $7 / 11$ or 0.64 . The reason for the shift to the left is not immediately apparent since the pK's of the two new ionizable groups, if isolated, would be similar to the phenolic groups they replaced. However, local electrostatic effects resulting from the presence of two positive charges separated by only three carbon atoms will facilitate the loss of $\mathrm{H}^{+}$and lower the $\mathrm{pK}$ of one of these groups. In addition, longer range electrostatic interactions (the molecule will gain eight positive charges) and inductive effects (resulting from attachment to a phenolic ring) will also tend to lower the pK's. These complex interactions make definitive predictions impossible, but the observed pK values of approximately 5.5 and 7.5 are consistent with the proposed structure.

The inhibitory effects of vancomycin fraction IV on ristocetin-induced platelet agglutination are shown in Table I. Increasing concentrations of vancomycin resulted in greater prolongation of the clumping time. Final concentrations of vancomycin slightly more than $10 \%$ of the final ristocetin concentration caused consistent prolongations. Increasing the ristocetin con-
TABLE I

Inhibition of Ristocetin-Induced Platelet Agglutination by Vancomycin

\begin{tabular}{cccccc}
\hline & \multicolumn{5}{c}{ Clumping time } \\
\cline { 2 - 6 } $\begin{array}{c}\text { Ristocetin } \\
\text { concentration }\end{array}$ & \multicolumn{5}{c}{ Vancomycin final concentration, $\mathrm{mg} / \mathrm{ml}$} \\
\cline { 2 - 6 } & 0 & 0.12 & 0.16 & 0.24 & 0.49 \\
\hline$m g / m l$ & & & & $s$ & \\
1.08 & 17 & 19 & 21 & 22 & 46 \\
0.97 & 18 & 20 & 22 & 24 & 51 \\
0.86 & 21 & 25 & 28 & 30 & 83 \\
0.75 & 26 & 31 & 30 & 37 & $>2$ min \\
0.65 & 30 & 50 & 56 & 65 & - \\
\hline
\end{tabular}

centration decreased the inhibition at each concentration of vancomycin tested. These studies are consistent with, but do not definitively prove, a competitive form of inhibition. Kinetic studies were performed to define whether vancomycin's inhibition acted by an effect on a platelet or plasma factor. Vancomycin was incubated with either the platelets or plasma for variable periods of time and the clumping time was then determined. As seen in Table II, preincubation with platelets for increasing periods of time caused a significant prolongation of the clumping time, but preincubation with plasma did not. The slight prolongation with the plasma incubations above the zero-time platelet incubation value can be accounted for by the 15-s incubation with platelets which, for technical reasons, occurred with all the plasma-preincubated specimens. After reaction with EDC in the presence of glycine methyl ester, vancomycin did not demonstrate a time-dependent inhibition of ristocetininduced platelet agglutination.

\section{TABLE II}

Comparison of the Inhibitory Effect of Vancomycin on Ristocetin-Induced Agglutination When Vancomycin is Preincubated with Platelets or Plasma

\begin{tabular}{ccc}
\hline \multirow{2}{*}{ Incubation time } & \multicolumn{2}{c}{ Clumping time } \\
\cline { 2 - 3 } & With platelets* & With plasmat \\
\hline$s$ & & $s$ \\
0 & 14 & 16 \\
15 & 16 & 17 \\
30 & 25 & 17 \\
45 & 24 & 17
\end{tabular}

The effect of preincubating vancomycin (final concentration $0.24 \mathrm{mg} / \mathrm{ml}$ ) with platelets or plasma before initiating agglutination with ristocetin (final concentration $0.54 \mathrm{mg} / \mathrm{ml}$ ). * No incubation with plasma.

f 15-s incubation with platelets occurred. 
Ristocetin-induced platelet aggregation of PRP was also inhibited by vancomycin fraction IV as evidenced by a decrease in the initial slope of aggregation. The control value was $5.8 \mathrm{OD} \mathrm{U} / \mathrm{min}$, whereas at final vancomycin concentrations of $0.22,0.43$, and $0.85 \mathrm{mg} / \mathrm{ml}$ the initial slope decreased to $4.6,4.0$, and $3.3 \mathrm{U} / \mathrm{min}$, respectively.

The electrometric titration data on vancomycin and its derivatives are shown in Fig. 6. If, as previous studies suggest, the acid titratable group(s) is a single carboxyl group, then five other groups are titratable at higher pH's, probably two amino and three phenolic groups. As with ristocetin, reacting vancomycin with EDC led to a higher plateau and shift to the left. The ratio of total micromoles $\mathrm{H}^{+}$dissociated for vancomycin to total micromoles for vancomycin-EDC was 0.71 . Since each phenolic group altered results in a net increase of one dissociatable $\mathrm{H}^{+}$, this suggests that the EDC reacted with two phenolic groups since this would give a theoretical ratio of $5 / 7$ or 0.71 . In addition to the changes in the alkaline range, reacting vancomycin with EDC in the presence of glycine methyl ester led to a loss of the acid-titratable group, that is, the carboxyl group. Subsequent reaction with hydroxylamine resulted in a shift in the alkaline $\mathrm{pK}$ 's back to that found with the unaltered vancomycin, confirming the restoration of the phenolic groups. As expected, the carboxyl group alteration was not affected by the hydroxylamine. The resulting compound has charge properties very similar to those of ristocetin in the neutral $\mathrm{pH}$ range.

Reaction of vancomycin with EDC in the presence of glycine methyl ester decreased the antibiotic activity to $9 \%$ of its original value. Subsequent reaction with hydroxylamine restored the antibiotic activity to $50 \%$ (average of two experiments) of its original value.

The platelet agglutinating ability of vancomycin fraction IV and its derivatives in the presence of plasma is shown in Table III. Neither vancomycin nor vancomycin + EDC agglutinated platelets in the presence of normal plasma. However, after subsequent reaction of the vancomycin + EDC with hydroxylamine, the derivative did agglutinate platelets in the presence of normal plasma. This agglutination was not supported by three plasmas from patients with severe von Willebrand's disease. The agglutination was not dependent on procoagulant factor VIII since two plasma from patients with hemophilia with less than $1 \%$ procoagulant factor VIII supported agglutination.

\section{DISCUSSION}

Our studies offer new insights into the biochemical mechanism of ristocetin-induced agglutination of platelets in the presence of the von Willebrand factor. Reacting ristocetin with a water-soluble

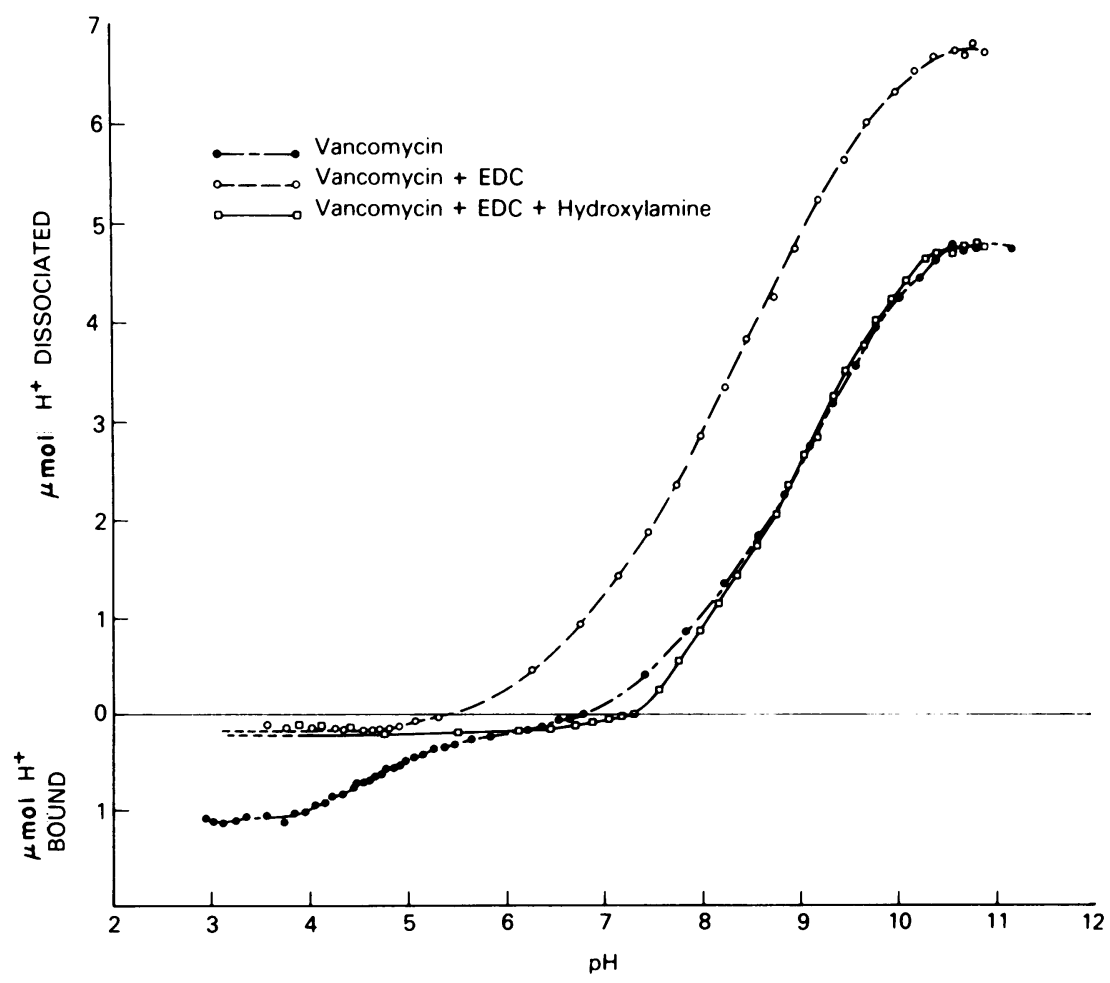

FIGURE 6 Electrometric titration of $3.0 \mathrm{mg}$ of vancomycin and its derivatives. 
TABLE III

Clumping Time

\begin{tabular}{|c|c|c|c|c|c|c|c|c|c|}
\hline & \multirow{2}{*}{$\begin{array}{l}\text { Exper- } \\
\text { iment }\end{array}$} & \multirow{2}{*}{$\begin{array}{c}\text { Final } \\
\text { concentration* }\end{array}$} & \multicolumn{2}{|c|}{ Normal plasma } & \multicolumn{3}{|c|}{ Severe von Willebrand plasma } & \multicolumn{2}{|c|}{$\begin{array}{c}\text { Hemophilic } \\
\text { plasma }\end{array}$} \\
\hline & & & I & II & I & II & III & I & II \\
\hline & & $\mathrm{mg} / \mathrm{ml}$ & & & & $s$ & & & \\
\hline Vancomycin & $\begin{array}{l}1 \\
2\end{array}$ & $\begin{array}{l}0.7 \\
0.9\end{array}$ & $\begin{array}{l}>2 \text { min } \\
>2 \text { min }\end{array}$ & & & & & & \\
\hline Vancomycin + EDC & $\begin{array}{l}1 \\
2\end{array}$ & $\begin{array}{l}0.7 \\
0.9\end{array}$ & $\begin{array}{l}>2 \mathrm{~min} \\
>2 \mathrm{~min}\end{array}$ & & & & & & \\
\hline $\begin{array}{c}\text { Vancomycin + EDC } \\
\text { + hydroxylamine }\end{array}$ & $\begin{array}{l}1 \\
2\end{array}$ & $\begin{array}{l}0.7 \\
0.9\end{array}$ & $\begin{array}{l}48 \\
63\end{array}$ & 66 & $\begin{array}{l}>2 \min \\
>2 \min \end{array}$ & $\begin{array}{l}>2 \text { min } \\
>2 \text { min }\end{array}$ & $\begin{array}{l}>2 \min \\
>2 \min \end{array}$ & $\begin{array}{l}40 \\
64\end{array}$ & $\begin{array}{l}65 \\
65\end{array}$ \\
\hline
\end{tabular}

* Concentrations calculated from $\mathrm{OD}_{280}$ using extinction coefficient for vancomycin.

carbodiimide at $\mathrm{pH} 4.75$ led to a decrease in both platelet agglutinating and antibiotic activities. Electrometric titration and spectrophotometric analysis supported alteration of phenolic groups (four of five by quantitative electrometric titration analysis) presumably yielding the $\mathrm{O}$-aryl isourea derivative. Both antibiotic and agglutinating activities, as well as the physicochemical characteristics of the compound, were partially or completely restored by subsequent reaction with hydroxylamine, lending further support to a phenolic group alteration. These data suggest that the phenolic group-dependent peptide-binding reaction previously implicated in ristocetin's antibiotic activity may also be crucial in its plateletagglutinating properties.

Vancomycin, which has antibiotic and peptidebinding properties similar to ristocetin, does not induce platelet agglutination as ristocetin does. In fact, our studies confirm the preliminary report (20) that vancomycin inhibits the ristocetin-induced platelet agglutination phenomenon in both the PRP and formalinized platelet systems. This inhibition appears to be specific for ristocetin-induced aggregation since, in our unpublished studies, vancomycin at a final concentration of $0.5 \mathrm{mg} / \mathrm{ml}$ did not inhibit ADP, epinephrine, or collagen-induced aggregation. Although not definitive, our studies suggest that the inhibition is of a competitive nature since increasing concentrations of ristocetin diminished the inhibition. In addition, vancomycin's inhibition seems to be produced by an effect on the platelet rather than on the von Willebrand factor since the inhibition increased over time when vancomycin was incubated with platelets but not with plasma. One possibility is that vancomycin occupied the ristocetin-binding sites on the platelet and thus prevented ristocetin's binding. This is reasonable since both antibiotics have similar binding properties.
In addition to a binding requirement, our studies on ristocetin and vancomycin also support a requirement for a net positive charge for platelet agglutination induction. We previously postulated that ristocetin required a net positive charge to induce agglutination since the upper $\mathrm{pH}$ limit of ristocetin-induced platelet agglutination (8.3-8.5) coincided with the isoionic point of ristocetin (8.2-8.3). Our studies confirm that vancomycin has a free carboxyl group in addition to amino and phenolic groups, and thus has a less positive net charge than ristocetin at neutral $\mathrm{pH}$. Two previous titration studies on vancomycin differed as to the number of amino groups on the molecule. This is important since it will make a difference in the net charge in the neutral $\mathrm{pH}$ range. Lomakina et al. (13) concluded that there were two amino groups and that the isoionic point of the antibiotic was 8.0. Nieto and Perkins (18) concluded that there was only a single amino group. Since more recent direct biochemical data by Smith et al. (25) support the presence of two amino groups in vancomycin, we favor this view. Reacting vancomycin with EDC resulted in a loss of antibiotic activity, and physicochemical analysis showed alterations of both phenolic and carboxyl groups. Subsequent reaction with hydroxylamine regenerated the phenolic groups and restored half of the original antibiotic activity but left the carboxyl group untitratable, that is, neutralized, with the glycine methyl ester derivative. This demonstrates that vancomycin's antibiotic activity is not completely dependent on the presence of its free carboxyl group and this was anticipated since ristocetin has antibiotic activity even though it lacks a free carboxyl group. In the neutral $\mathrm{pH}$ range, the hydroxylamine-treated vancomycin + EDC compound has charge properties very similar to ristocetin's since both compounds have net charges of +2 at a $\mathrm{pH}$ of approximately 5.5 (as compared to a $\mathrm{pH}$ of about 3.75 for 
unaltered vancomycin), will be uncharged at a $\mathrm{pH}$ between 8 and 9 , and will have intermediate charges between these values.

Neither vancomycin nor vancomycin + EDC induced platelet agglutination in the presence of the von Willebrand factor. However, after hydroxylamine treatment restored its phenolic groups, the resulting compound, having charge properties like ristocetin's, agglutinated platelets as ristocetin does, that is, in the presence of normal or hemophilic plasma but not severe von Willebrand plasma. These data suggest that there are both binding and charge requirements for ristocetin-induced agglutination.

In constructing a model of ristocetin-induced platelet agglutination, it is crucial to know which of the three elements (platelet, von Willebrand factor, ristocetin) interact specifically with each of the others. Unfortunately little direct experimental data is available. In our study, vancomycin's inhibition seemed to be based on its interaction with platelets since preincubation with platelets enhanced the inhibition but preincubation with plasma did not. If vancomycin is, in fact, acting as competitive inhibitor by occupying ristocetin-binding sites, then it is most probable that ristocetin has a direct interaction with the platelet. Other indirect evidence for this interaction derives from the observation that the addition of ristocetin to formalinized platelets stirred in an aggregometer in the absence of plasma results in a decrease in the light transmittance of the platelet suspension (9). Direct evidence for the binding of ristocetin to the platelet surface awaits the availability of a suitable tracer molecule.

If ristocetin does bind to the platelet, it may do so by a mechanism similar to its binding properties with peptides. The latter phenomenon has an absolute requirement for a terminal ionized carboxyl group on the peptide (14). Seaman estimated that each platelet has approximately $16.4 \times 10^{5}$ free carboxyl groups detectable at its surface (26). He concluded that approximately $57 \%$ of these carboxyl groups are associated with sialic acid residues whereas the remainder are probably associated with amino acid residues. These carboxyl groups, along with a minor contribution from phosphate and sulfhydryl groups, result in the platelet having a strong net negative charge. At neutral $\mathrm{pH}$, the binding of positively charged ristocetin to the platelet's carboxyl groups could result in a decrease in the platelet's net negative charge. Depending on the relationship between the sites of ristocetin binding and the platelet's surface of shear, this could lead to a reduction in the platelet's zeta potential and a resultant drop in the electrostatic repulsion between platelets. There is significant evidence that the normal electrostatic repulsion between platelets plays a vital role in the pre- vention of platelet aggregation and that the induction of aggregation by a variety of agents is associated with a reduction of the zeta potential $(27,28)$. Greenberg et al. showed that reducing the platelet's zeta potential by neuraminidase treatment enhanced ristocetin-induced aggregation in the presence of normal plasma (29) and Kirby and Mills showed that similar treatment of formalinized platelets enhanced bovine Factor VIII-induced platelet agglutination (a process analogous to human von Willebrand factor agglutination, except that ristocetin is not needed to initiate the reaction) (30). Thus a reduction in net platelet surface charge facilitates platelet-platelet interactions and our data on the $\mathrm{pH}$ requirements of ristocetin-induced aggregation are consistent with ristocetin needing a net positive charge to induce aggregation. We considered that ristocetin's effect might simply be due to it being a positively charged molecule in the solution. However, our unpublished observations on the effect of $\mathrm{pH}$ on formalinized platelets do not support this hypothesis. We noted that washed, formalinized platelets will spontaneously agglutinate if the $\mathrm{pH}$ of the medium is reduced to approximately $4.5-5 .^{2}$ This presumably results from a decrease in zeta potential (approximately $20 \%$ by reference to Seaman and Vassar's study on acetaldehyde-treated platelets or roughly equivalent to the effect of $2.3 \mu \mathrm{M}$ ADP on citrated platelets (31)). There was no difference, however, in the $\mathrm{pH}$ reduction needed for platelet agglutination in the presence of normal plasma or von Willebrand plasma as one might have predicted if the hydrogen ions were acting like ristocetin. Further evidence against a nonspecific cationic effect for ristocetin's action is the inability of the EDC derivative to induce agglutination despite its greater positive charge than was on the original ristocetin molecule. Thus, ristocetin's positive charge appears to be necessary but not sufficient to induce agglutination in the presence of the von Willebrand factor and the specificity of its effect most likely resides in its binding reaction.

Still unresolved, however, is the molecular events accounting for the attachment of one platelet to another. We believe that several lines of evidence support the hypothesis that the von Willebrand factor itself may act as a bridging molecule between platelets. Firstly, biochemical studies on the von Willebrand factor in our own and other laboratories (32-34) have identified it as a macromolecular (molecular weight $>1.2$ million) glycoprotein made up of identical subunits held together by disulfide bonds. Both its large size and repetitive subunit structure make it analogous to an IgM molecule and, like the latter, these features

\footnotetext{
${ }^{2}$ Coller, B. S. Unpublished observation.
} 
make it an ideal candidate for causing agglutination. In addition, we and others have identified the intimate relationship between the von Willebrand factor and the platelet $(35,36)$ and it is likely that a specific platelet receptor mechanism (37) which recognizes the carbohydrate portion of the von Willebrand factor is involved in this association (38).

Since the von Willebrand factor also carries a net negative charge at neutral $\mathrm{pH}$, there will also be a net repulsive force between it and the platelet. It is possible that ristocetin selectively reduces the negative charge near the platelet's von Willebrand factor receptor and thus facilitates this interaction. Recent reports showing a requirement for ristocetin in the binding of exogenous von Willebrand factor to platelets are consistent with this mechanism $(39,40)$.

As a unifying working hypothesis, we propose that in the normal state the electrostatic repulsion between platelets prevents their getting close enough to each other to be bridged by the von Willebrand factor. When ristocetin is added, it binds, via its phenolic groups, to the platelet surface, most likely at protein-associated free carboxyl groups. Being positively charged, the bound ristocetin reduces the net negative charge on the platelet surface and permits closer contact between platelets. This, in turn, permits the von Willebrand factor to bridge between platelets resulting in agglutination. Alternatively or additionally, ristocetin may selectively reduce the negative charge near the von Willebrand factor receptor, permitting the fluid phase von Willebrand factor to more easily bind to the platelet to initiate agglutination. Vancomycin can also bind to the platelet surface, but since its own free carboxyl group makes it less positively charged, it cannot reduce the platelet's negative charge as ristocetin does. By occupying the ristocetin-binding sites on the platelet surface, it actually inhibits ristocetin-induced agglutination. When its charge properties are made more like those of ristocetin (while still preserving its binding properties) it can induce agglutination in the presence of the von Willebrand factor as ristocetin does.

Data derived from studies of the Bernard-Soulier syndrome might appear to conflict with the above hypothesis. The platelets in this disorder have decreased sialic acid content and a less negative electrophoretic mobility (41), which should result in a reduction in electrostatic repulsion between platelets and enhanced agglutination. Instead, these platelets do not agglutinate with ristocetin even in the presence of von Willebrand factor. However, the membrane glycoprotein which is deficient and/or abnormal in this disorder (6) appears to be crucial in the attachment of von Willebrand factor to the platelet since these platelets will not bind von Willebrand factor even in the presence of ristocetin (40). Thus, despite the electrostatic advantage the platelets have for agglutination, the inability to bind the bridging molecule is of greater importance in determining whether agglutination will or will not occur.

\section{ACKNOWLEDGMENTS}

We would like to thank Ms. Stasia Burt for excellent technical assistance, Dr. Harry Saroff for advice in the titration studies, and Mrs. Lynda Ray and Mrs. Marty Auman for excellent secretarial assistance. We would also like to thank Dr. James Maclowry for performing the antibiotic activity studies.

\section{REFERENCES}

1. Howard, M. A., and B. G. Firkin. 1971. Ristocetina new tool in the investigation of platelet aggregation. Thromb. Diath. Haemorrh. 26: 362-369.

2. Weiss, H. J., J. Rogers, and H. Brand. 1973. Defective ristocetin-induced platelet aggregation in von Willebrand's disease and its correction by factor VIII. $J$. Clin. Invest. 52: 2697-2707.

3. Meyer, D., C. S. P. Jenkins, D. Dreyfus, E. Fressinand, and M-J. Larrieu. 1974. von Willebrand factor and ristocetin. II. Relationship between Willebrand factor, Willebrand antigen and factor VIII activity. Br. J. Haematol. 28: 579-599.

4. Weiss, H. J., T. B. Tschopp, H. R. Baumgartner, I. Sussman, M. M. Johnson, and J. J. Egan. 1974. Decreased adhesion of giant (Bernard-Soulier) platelets to subendothelium. Am. J. Med. 57: 920-925.

5. Allain, J. P., H. A. Cooper, R. H. Wagner, and K. M. Brinkhous. 1975. Platelets fixed with paraformaldehyde: a new reagent for assay of von Willebrand factor and platelet aggregating factor. J. Lab. Clin. Med. 85: 318328.

6. Jenkins, C. S. P., D. R. Phillips, K. J. Clemetson, D. Meyer, M-J. Larrieu, and E. F. Luscher. 1976. Platelet membrane glycoprotein implicated in ristocetin-induced aggregation. Studies of the proteins on platelets from patients with Bernard-Soulier syndrome and von Willebrand's disease. J. Clin. Invest. 57: 112-124.

7. Howard, M. A. 1975. Inhibition and reversal of ristocetininduced platelet aggregation. Thromb. Res. 6: 489-499.

8. Kattlove, H. E., and M. H. Gomez. 1975. Studies on the mechanism of ristocetin-induced platelet aggregation. Blood. 45: 91-96.

9. Kirby, E. P. 1975. Evans Blue: a specific inhibitor of factor VIII-induced platelet agglutination. Thromb. Diath. Haemorrh. 34: 770-779.

10. Coller, B. S., B. R. Franza, Jr., and H. R. Gralnick. 1976. The $\mathrm{pH}$ dependence of quantitative ristocetin-induced platelet aggregation: theoretical and practical implications-a new device for maintenance of platelet-rich plasma pH. Blood. 47: 841-854.

11. Coller, B. S., and H. R. Gralnick. 1976. Biochemical mechanism of ristocetin-induced platelet agglutination. Clin. Res. 24: 305A. (Abstr.)

12. Perkins, H. R., and M. Nieto. 1974. The chemical basis for the action of the vancomycin group of antibiotics. Ann. N.Y. Acad. Sci. 235: 348-363.

13. Lomakina, N. N., L. I. Muravieva, and M. S. Yurina. 1970. Molecular weight and the number of ionogenic groups of ristomycins and close antibiotics. Antibiotiki (Mosc.). 15: 21-24. 
14. Nieto, M., and H. R. Perkins. 1971. The specificity of combination between ristocetins and peptides related to bacterial cell wall mucopeptide precursors. Biochem. J. 124: 845-852.

15. MacFarlane, D. E. Inhibition of bovine factor VIII and ristocetin plus human factor VIII-induced platelet agglutination by small peptides. Proceedings of the 5th Congress of the International Society of Thrombosis and Haemostasis, Paris, France, July, 1975. 276. (Abstr.)

16. Smith, G. A., K. A. Smith, and D. H. Williams. 1975. Structural studies on the antibiotic vancomycin: evidence for the presence of modified phenyl glycine and $\beta$ hydroxytyrosine units. J. Chem. Soc. Perkins Trans. I. 2108-2115.

17. Kirby, W. M. M., and C. L. Divelbiss. Vancomycin: clinical and laboratory studies. In Antibiotics Annual 1956-57. Medical Encyclopedia, Inc., New York. 107.

18. Nieto, M, and H. R. Perkins. 1971. Physicochemical properties of vancomycin and iodovancomycin and their complexes with diacetyl-L-lysyl-D-alanyl-D-alanine. Biochem. J. 123: 773-787.

19. Coller, B. S., W. B. Lundberg, and H. R. Gralnick. 1975. Effects of vancomycin on platelets, plasma proteins and hepatitis B surface antigen. Thromb. Diath. Haemorrh. 34: 83-93.

20. Roper, P:, D. M. Peterson, and J. L. Moake. 1975. Vancomycin inhibition of platelet aggregation induced by ristocetin, collagen and ADP. Abstracts of the American Society for Hematology, December 1975. 201.

21. Hoare, D. G., and D. E. Kosshland, Jr. 1967. A method for the quantitative modification and estimation of carboxylic acid groups in proteins. J. Biol. Chem. 242: 2447-2453.

22. Carraway, K. L., and D. E. Koshland, Jr. 1968. Reaction of tyrosine residues in proteins with carbodiimide reagents. Biochim. Biophys. Acta. 160: 272-274.

23. Code of Federal Regulations. 1972. Food and Drugs. U. S. Government Printing Office, Wash., D. C. Vol. 21.

24. Coller, B. S., and H. R. Gralnick. 1976. The effect of stir bar size and shape on quantitative platelet aggregation. Thromb. Res. 8: 121-129.

25. Smith, K. A., D. H. Williams, and G. A. Smith. 1974. Structural studies on the antibiotic vancomycin: the nature of the aromatic rings. J. Chem. Soc. Perkin I. 2369-2376.

26. Seaman, G. V. F. 1976. Electrochemical features of platelet interactions. Thromb. Res. 8 (Suppl. II): 235-246.

27. Dawber, J. G., and J. C. Roberts. 1968. An electrical double layer theory for platelet adhesiveness and ini- tiation of intravascular thrombosis. Thromb. Diath. Haemorrh. 19: 451-458.

28. Seaman, G. V. F., and D. E. Brooks. 1970. Electrochemical aspects of platelet adhesion and aggregation. Thromb. Diath. Haemorrh. 42 (Suppl.): 93-107.

29. Greenberg, J., M. A. Packham, J-P. Cazenave, H-J. Reimers, and J. F. Mustard. 1975. Effects on platelet function of removal of platelet sialic acid by neuraminidase. Lab. Invest. 32: 476-484.

30. Kirby, E., and D. C. B. Mills. 1975. The interaction of bovine factor VIII with human platelets. J. Clin. Invest. 56: $491-502$.

31. Seaman, G. V. F., and P. S. Vassar. 1966. Changes in the electrokinetic properties of platelets during their aggregation. Arch. Biochem. Biophys. 117: 10-17.

32. Shapiro, G. A., J. C. Andersen, S. V. Pizzo, and P. A. McKee. 1973. The subunit structure of normal and hemophilic factor VIII. J. Clin. Invest. 52: 2198-2210.

33. Legaz, M., G. Schmer, R. Counts, and E. W. Davie: 1973. Isolation and characterization of human factor VIII (antihemophilic factor). J. Biol. Chem. 248: 3946-3955.

34. Gralnick, H. R., and B. S. Coller. 1975. Studies of the human factor VIII/von Willebrand factor protein. II. Identification and characterization of the von Willebrand protein. Blood. 46: 417-430.

35. Coller, B. S., R. J. Hirschman, and H. R. Gralnick. 1975. Studies of the factor VIII/von Willebrand factor antigen on the platelet surface. Thromb. Res. 6: 469-480.

36. Howard, M. A., D. C. Montgomery, and R. M. Hardisty. 1974. Factor VIII-related antigen in platelets. Thromb. Res. 4: 617-624.

37. Jaffe, E. A., and R. L. Nachman. 1975. Factor VIII binding protein in human platelets. Clin. Res. 23: 276A. (Abstr.)

38. Gralnick, H. R., B. S. Coller, and Y. Sultan. 1976 Carbohydrate deficiency of the factor VIII/von Willebrand factor protein in von Willebrand's disease variants. Science (Wash. D.C.). 192: 56-59.

39. Green, D., and E. V. Potter. 1976. Platelet-bound ristocetin aggregation factor in normal subjects and patients with von Willebrand's disease. J. Lab. Clin. Med. 87: 976-986.

40. Zucker, M. B., K. Sook-Ja, J. McPherson, and R. A. Grant. 1977. Binding of factor VIII to platelets in the presence of ristocetin. Br. J. Haematol. 35: 535-549.

41. Gröttum, K. A., and N. O. Solum. 1969. Congenital thrombocytopenia with giant platelets: a defect in the platelet membrane. Br. J. Haematol. 16: 277-290. 